\title{
Integration of onshore and offshore seismic arrays to study the seismicity of the Calabrian Region: a two steps automatic procedure for the identification of the best stations geometry
}

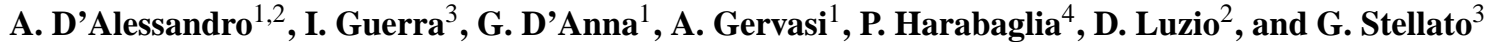 \\ ${ }^{1}$ Istituto Nazionale di Geofisica e Vulcanologia, Centro Nazionale Terremoti, Rome, Italy \\ ${ }^{2}$ Università di Palermo, Dipartimento delle Scienze della Terra e del Mare, Palermo, Italy \\ ${ }^{3}$ Università della Calabria, Dipartimento di Fisica, Arcavacata di Rende (Cosenza), Italy \\ ${ }^{4}$ Università della Basilicata, Scuola di Ingegneria, Potenza, Italy
}

Correspondence to: A. D’Alessandro (antonino.dalessandro@ingv.it)

Received: 24 May 2014 - Accepted: 21 July 2014 - Published: 22 August 2014

\begin{abstract}
We plan to deploy in the Taranto Gulf some Ocean Bottom broadband Seismometer with Hydrophones. Our aim is to investigate the offshore seismicity of the Sibari Gulf. The seismographic network optimization consists in the identification of the optimal sites for the installation of the offshore stations, which is a crucial factor for the success of the monitoring campaign. In this paper, we propose a two steps automatic procedure for the identification of the best stations geometry. In the first step, based on the application of a set of a priori criteria, the suitable sites to host the ocean bottom seismic stations are identified. In the second step, the network improvement is evaluated for all the possible stations geometries by means of numerical simulation. The application of this procedure allows us to identify the best stations geometry to be achieved in the monitoring campaign.
\end{abstract}

\section{Introduction}

The Pollino Massif (Southern Italy) is a stocky mountain chain, triangle-shaped and E-W oriented which marks the transition from the Southern Apennines to the Calabrian Arc. On the western side it is characterized by a moderate seismicity $\left(9 M_{\mathrm{L}}>4\right.$ events in the last 50 years, Fig. 1a), rather well documented in the last 400 years (Peresan and Panza, 2002; Castello et al., 2006; Luzi et al., 2008; Rovida et al., 2011; Iside catalog). The Moment Tensor Solutions (MTS) available in this area (Fig. 1b, European-Mediterranean CMT catalog; Ekström et al., 2012) mainly yields normal faults with coherent Southern Apenninic trend. This remains true also for several tens of Fault Plane Solutions of the dense seismic sequence, which interested the western Pollino area in the years 2010-2012 (Totaro et al., 2013). South of the Massif, in most of the Sibari plane, seismic activity is very scarce, while it is again rather intense in its southeastern corner, both onshore and offshore. There are however only a few MTS in this south-eastern part of the area; two of them show the right strike slip kinematics of the associated events, with of the possible fault planes coherent with the Southern Apenninic trend, while the third one derives from a thrust event in the perpendicular direction. It is also noteworthy that at least a couple of MTS around the Sila Massif still yield a Southern Apenninc trend. The morphology also presents some Southern Apenninic trend: the Pollino Massif crests and valley do show it, as well as the shore direction from the Sibari Plain up to Cirò Marina.

The above observations point to the perspective that the stress field of a vast portion of Northern Calabria still resembles that of the Southern Apennines (Guerra et al., 2005). In this frame, it becomes important to investigate the offshore seismicity of the Sibari Gulf and the deformation pattern within the Sibari Plane. The latter might function as a hinge to transfer the deformation of the extensional fault system in the Pollino area to a different offshore fault system. Since return times of largest events might be very long, we need to investigate the true seismic potential of the offshore faults and to verify whether they are truly strike slip or if they could 
(a)

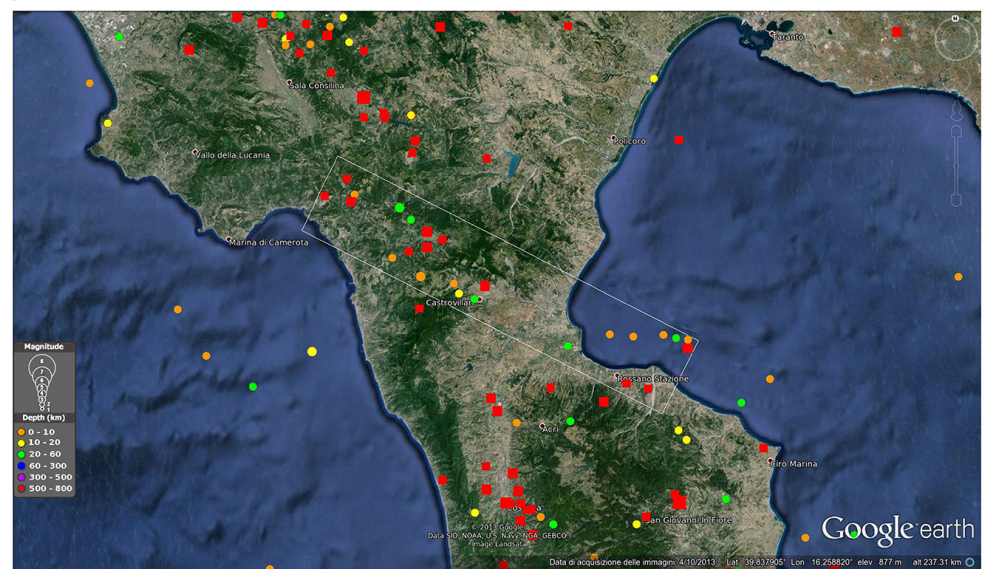

(b)

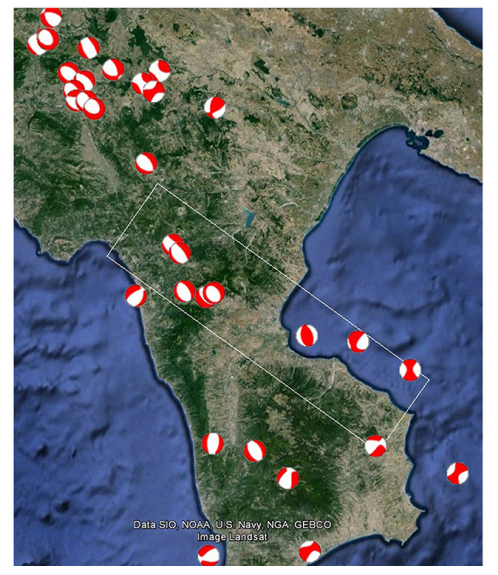

Figure 1. (a) Instrumental (full circle) and historical seismicity (red square) of the study area (earthquake with $M>4$, data from UCI2001 (1960-1980), CSI (1981-2002), ITACA (2003-2005/04/15), ISIDE 2005/04/16-today and CPTI11 (1000-1959) catalogs; (b) Moment Tensor solutions from Global Centroid-Moment-Tensor and European-Mediterranean Regional Centroid Moment Tensor catalogs; the white rectangle in both the figures indicates the area of main interest.

involve relevant thrust or normal components, that would add to the risk of potentially associated tsunamis.

The seismicity of the Calabrian area is monitored by the Italian National Seismic Network (INSN) managed by Istituto Nazionale di Geofisica e Vulcanologia and by the Calabrian University Seismic Network (CUSN) managed by the University of Calabria (D'Alessandro et al., 2013a). Both network comprise only on-land seismic stations (Fig. 2a). The lack of offshore stations does not allow accurate determination of the hypocentral parameters also for moderatestrong earthquakes that occur in the Calabrian offshore (D'Alessandro et al., 2013a). Figure 2b shows the spatial distribution of the location uncertainty in the study area determined integrating INSN and CUSN.

The location uncertainty has been determined for $M_{\mathrm{L}}=$ 1.5 and hypocentral depth of $10 \mathrm{~km}$ using the SNES method (D'Alessandro et al., 2011a, 2013a). Figure 2b report the Radius of the Equivalent Sphere (RES) parameter, which is the radius of the sphere whose volume equals that of the $95 \%$ confidence ellipsoid of the hypocentral parameters (D'Alessandro et al., 2011a). D'Alessandro et al. (2013a), observed that only few stations will detect small magnitude earthquakes in the offshore area of the Sibari Gulf, with resulting azimuthal gap exceeding $180^{\circ}$ and location errors of several kilometers (Fig. 2b). The lack of offshore seismic stations also does not allow the accurate determination of hypocentral coordinates and focal parameters also for even the largest earthquakes commonly observed in the investigated area.

With the aim of investigating the near shore seismicity in the Sibari offshore and its eventual relationship with the Pollino activity, we plan to deploy some OBS/H in the Taranto Gulf. The monitoring campaign is planned for the
2015, and it will last about a year. The equipment will consist in five OBS $/ \mathrm{H}$, each equipped with a broadband seismometer and a hydrophone.

The stations will be designed, assembled and deployed by the Gibilmanna OBSLab, a laboratory created in 2005 by INGV to address the offshore extension of the Italian seismic network (Mangano et al., 2011) and for the development of seismic station based on Micro Electro-Mechanical Systems (MEMS) technology (D'Alessandro and D'Anna, 2013). Several seismic monitoring experiments, conducted in the Mediterranean Sea have already resulted in a better understanding of the seismo-tectonic and seismo-volcanic activity of some submarine seismogenic districts (D'Alessandro et al., 2009, 2012a, 2013b, D’ Alessandro, 2014; Adelfio et al., 2012).

Due to the high costs and limited available resources, the network optimization, consisting in the identification of the optimal sites for the installation of the offshore stations, is a crucial factor for the success of the monitoring campaign. In the following, we analyze, by means of numerical simulations, the effect of the OBS/H stations in terms of network coverage and of hypocentral localization improvement. The results of the simulations are critically analyzed in order to identify the best OBS/H geometry, which will be realized in the monitoring campaign.

\section{Evaluation of the best $\mathrm{OBS} / \mathrm{H}$ array geometry}

In planning a monitoring campaign, it is necessary to find an optimal set of observation sites. They will ensure the widest and most homogeneous coverage of the area of interest, with a significant improvement of hypocenter estimation. They normally be selected among a larger set of possible candidate 
(a)

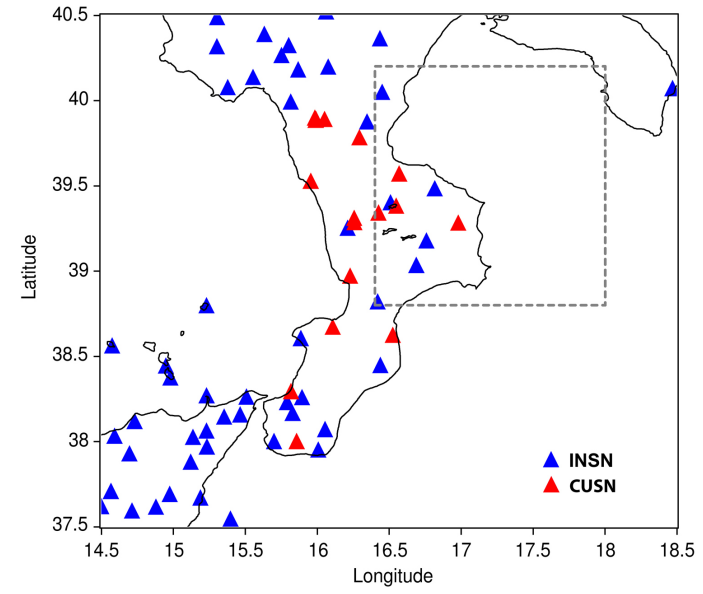

(b)

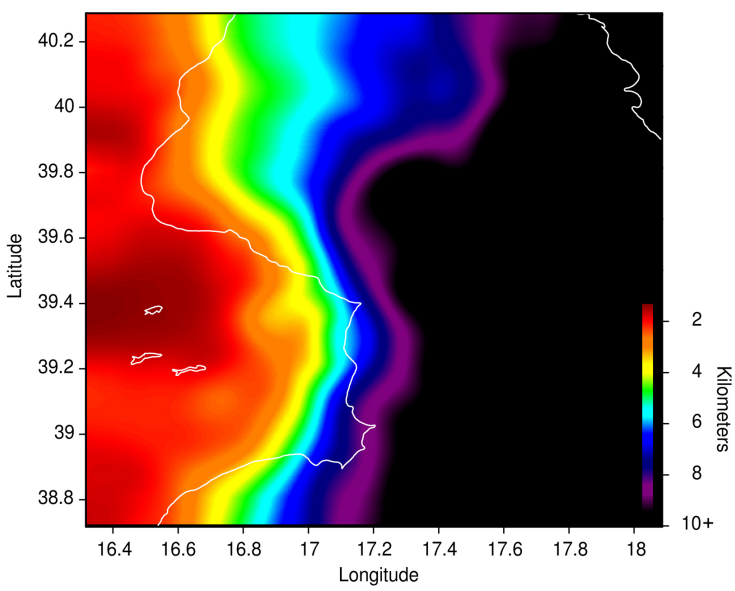

Figure 2. (a) distribution of the seismic stations on the Calabrian territory; (b) RES maps at $M_{\mathrm{L}}=1.5$, hypocentral depth of $10 \mathrm{~km}$ and confidence level of $95 \%$, for INSN+CUSN (D'Alessandro et al., 2013a).

locations and must ensure integration with the onshore stations.

The candidate sites to host an OBS/H station must satisfy the following requirements:

- $6 \mathrm{~km}$ maximum water depth;

$-5^{\circ}$ maximum average slope in an circular area of radius of $5 \mathrm{~km}$;

- $10 \mathrm{~km}$ minimum distance from the coastline;

- $10 \mathrm{~km}$ minimum distance among the stations.

The first constrain originates from the maximum operating depth of the OBS/H of $6 \mathrm{~km}$ (Mangano et al., 2011). The second one from the need that each OBS/H is deployed in a flat nearly horizontal area wide enough to prevent station or sensor overturnings. Even areas of moderate slope can compromise the sensor leveling and therefore the quality of the acquired signals. The third criterion is necessary in order to reduce the seismic noise power on the OBS/H signals. It is well known that wave breaking on the coastline is a strong source of noise. In addition, human activities near the coasts are generally intense and could be an additional source of noise. Finally, the fourth point is related to the ration between the extension of the study area and the number of measurement points and to a reasonable minimum stations spacing.

Figure 3 shows the bathymetric maps of the Taranto Gulf. The locations of the onshore seismic stations and of the candidate sites for $\mathrm{OBS} / \mathrm{H}$ installation are indicated. Because the maximum depth in the Taranto Gulf is about $3 \mathrm{~km}$, the candidate sites were identified only on the basis of the three remaining criteria. Starting from the whole set of sites, which fulfill the condition 2, an automatic search algorithm identified seven sites that would be suitable to host an OBS/H station (Fig. 3).

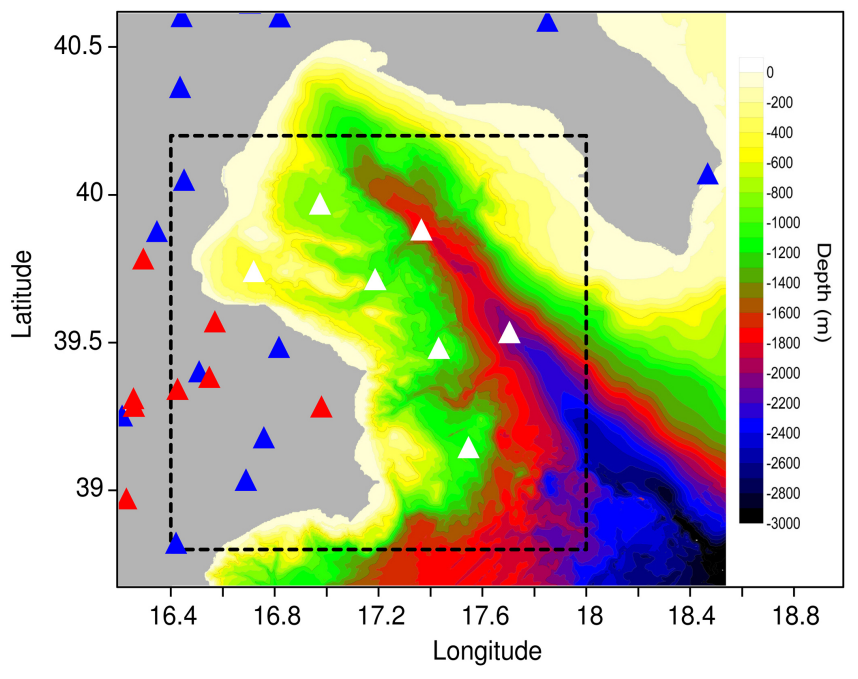

Figure 3. Bathymetric map of the Taranto Gulf; the dashed square indicates the area of main interest; blue triangles are INSN stations, red triangles are CUSN stations, white triangles are candidate sites for $\mathrm{OBS} / \mathrm{H}$ installation.

Since the possible sites are seven but there are only five available $\mathrm{OBS} / \mathrm{H}$, the number of possible stations geometries is 21. Therefore, it becomes crucial to identify an optimal OBS/H geometry, capable to ensure the best coverage of the area of interest, in view of both the limited number of suitable sites and of OBS/H.

To this purpose, we have simulated all the possible different $\mathrm{OBS} / \mathrm{H}$ geometries and we analyzed them by means of the SNES method (D'Alessandro et al., 2011a). This method has been extensively used for seismic networks performance evaluation (D'Alessandro et al., 2011b, 2012b, c, 2013c; D'Alessandro and Rupert, 2012) and optimization 

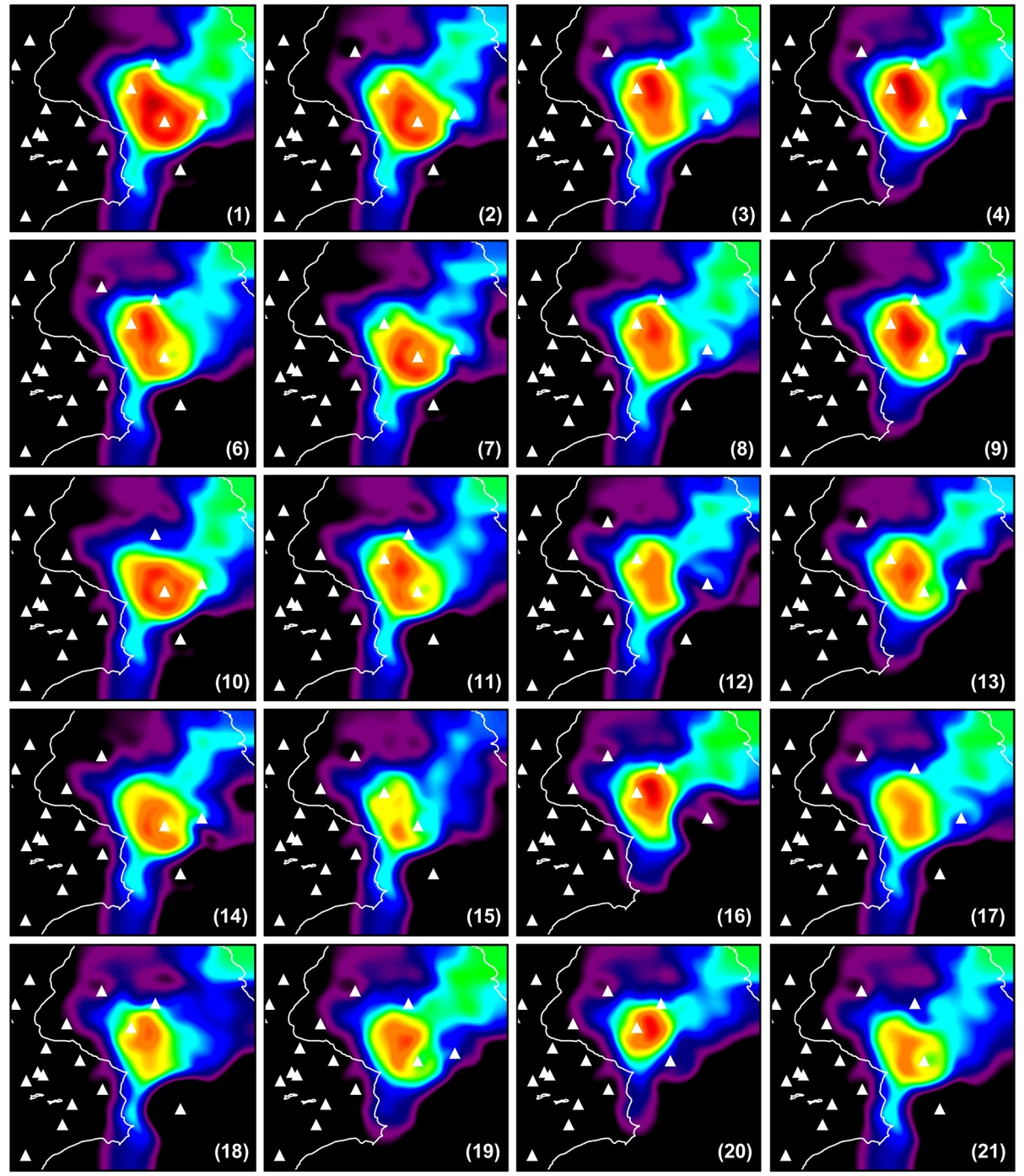

Figure 4. Improvement maps for the area of interest as average RES over all the investigated hypocenter depths, for different stations geometry; white triangles indicates the stations position; geometry 5 is showed in Fig. 6.

(D'Alessandro et al., 2013d). The SNES method allows to determine, as a function of magnitude, hypocentral depth and confidence level, the spatial distribution of the following parameters: magnitude detection threshold, number of stations active in the location procedure, azimuthal gap and confidence levels of hypocentral parameters. Details on the method and on the computation algorithms can be found in D'Alessandro et al. (2011a).

On the basis of the results of D'Alessandro et al. (2013a) and of the features of the local seismicity, the SNES maps were determined for $M_{\mathrm{L}}=1.5$ and hypocentral depths of $5,10,15,20,25$ and $30 \mathrm{~km}$, with $95 \%$ confidence intervals. In our evaluation, we considered only the RES parameter because it takes into account both epicentral and hypocentral depth errors, and is therefore the best parameter to quantify the performance of a seismic network. To quantify the improvement of the network due to the addition of five OBS/H in the candidate sites, we have determined, for each possible stations geometry, the difference between the RES maps with and without the offshore stations.

Figure 4 shows, for the area of interest and for all the possible stations geometries, the improvement maps as average RES determined over all the investigated hypocenter depths. The area of greatest improvement is located in the southwestern part of Taranto Gulf, where the RES reduction reaches values of about $7 \mathrm{~km}$.

The shape and the extension of the improvement area is clearly dependent on the OBS/H geometry. It is very difficult to identify the best OBS/H geometry by a simple visual inspection. This means that we need objective quantitative criteria. 

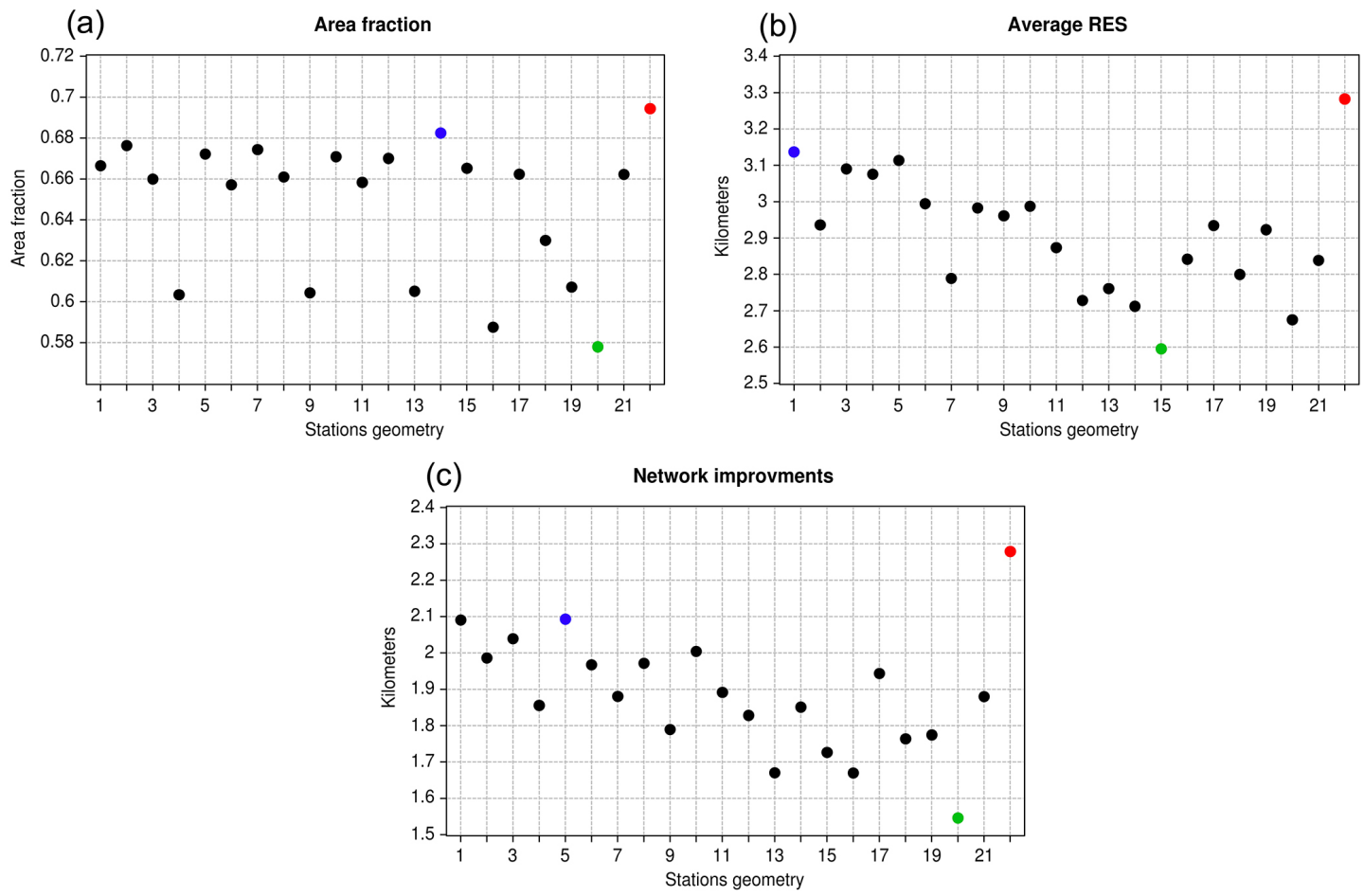

Figure 5. (a) $A_{\mathrm{RES}}$, (b) $\overline{\mathrm{RES}}$ and (c) $I\left(A_{\mathrm{RES}}, \overline{\mathrm{RES}}\right)$ as function of OBS/H geometry of Fig. 4; station geometry 22 refers to that assuming seven OBS/H (Fig. 6).

Therefore, to identify the optimal OBS/H geometry we determined:

- fraction of area in which there is a significant reduction of the hypocentral error $\left(A_{\mathrm{RES}}\right)$;

- average error reduction in this area $(\overline{\mathrm{RES}})$;

- improvement index $\left(I\left(A_{\mathrm{RES}}, \overline{\mathrm{RES}}\right)\right)$.

$A_{\text {RES }}$ is determined as the ratio between the area where RES reduction is more than $0.5 \mathrm{~km}\left(A_{\mathrm{IMP}}\right)$ and the area of interest $\left(A_{\mathrm{TOT}}\right) ; \overline{\mathrm{RES}}$ is determined as average RES in $A_{\mathrm{IMP}}$; $I\left(A_{\mathrm{RES}}, \overline{\mathrm{RES}}\right)$ is determined as $A_{\mathrm{RES}} \cdot \overline{\mathrm{RES}}$.

Figure 5 shows the distribution of these parameters as functions of the network geometry. In Fig. 6 we compare network geometry number 5 , our preferred one, with a hypothetical configuration with all sites occupied by OBS/H (stations geometry 22).

On the basis of Fig. 5, we can see that the fraction of area covered using only five OBS/H ranges between 0.682 (stations geometry 14) and 0.578 (stations geometry 20) and would be 0.694 using all the seven candidate sites. The average error reduction RES ranges between $3.136 \mathrm{~km}$ (stations geometry 1) and $2.595 \mathrm{~km}$ (stations geometry 15), and would be $3.282 \mathrm{~km}$ using all the seven candidate sites. The improvement index ranges between $2.092 \mathrm{~km}$ (stations geometry 5) and $1.545 \mathrm{~km}$ (stations geometry 20), and would be $2.278 \mathrm{~km}$ using all the seven candidate sites.

\section{Discussion and conclusion}

The seismicity and the seismogenic volumes of the Sibari Gulf are not well characterized, despite their importance in the understanding of the seismotectonic processes in the Southern Apenninic - Calabrian Arc border and surrounding areas. The main reason is the poor distribution of the seismic network sensors due to the elongated shape of the Calabrian arc and in the lack of offshore stations.

With the aim of investigating the near shore seismicity in the Sibari offshore and its eventual relationship with the Pollino activity, we plan to deploy several OBS/H in the Taranto Gulf. The monitoring campaign, planned for the 2015, will allow for the acquisition of a large amount of data. Their integration with those acquired by the onshore permanent networks will help in characterizing the seismicity and the seismogenetic volume of this area.

A careful assess stations geometry is of primary importance in any monitoring campaign. This is especially true when submarine stations are involved. This assessment must take into account both the presence of pre-existing networks and the logistical problems due to the deployment of the OBS/H. An optimal stations geometry must be achieved, that is the one with the largest are coverage and the greatest reduction in the hypocentral error. 

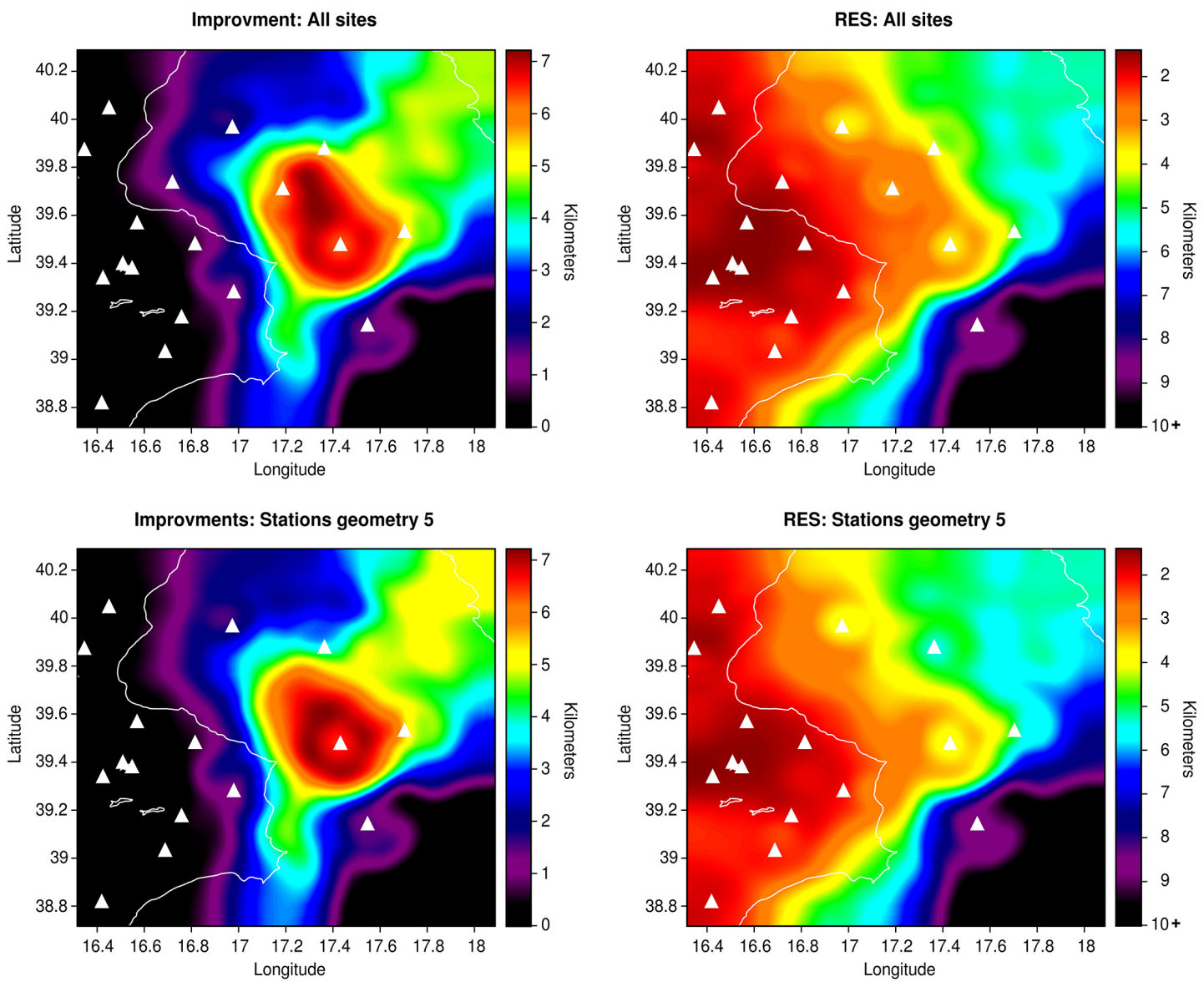

Figure 6. Improvement and RES maps using the stations geometry 5 and assuming seven OBS/H.

In this paper, we propose a two steps automatic procedure for the identification of the best stations geometry. In the first step, we identify suitable sites to host OBS/H stations, based on some a priori criteria. In the second step we evaluate the network improvement for all the possible stations geometries. We specifically identify seven candidate site suitable to host the five OBS/H planned for the monitoring campaign; this led to a total of 21 possible stations geometries.

The results of our simulation shows that for $M_{\mathrm{L}}=1.5$, on the basis of $A_{\mathrm{RES}}$, the OBS/H geometry 14 should be surely the best, although many geometries could ensure a very similar coverage. However, seven geometries have to be excluded $(4,9,13,16,18,19,20)$ because they do not provide a sufficient extension of the area covered by the network. On the basis of $\overline{R E S}$ the best station geometry should be the array 1 , even though similar values are obtained for the geometries 3 , 4 and 5. However these parameters, separately, do not permit to univocally determine the best OBS/H array. The analysis of the improvement index $I\left(A_{\text {RES }}, \overline{\text { RES }}\right)$ instead, allow us to identify in geometry 5 (Fig. 6) the best one and, as second choice, geometry 1 . The array number 20 is that with the minimum $I\left(A_{\mathrm{RES}}, \overline{\mathrm{RES}}\right)$ and than should be avoided.
Figure 6 compares the improvement and RES maps relative to geometry 5 and to the ideal seven OBS/H geometry. We can see that the use of geometry 5 greatly improves the location performance in most of the area of our interest and by using two further OBS/H's we will not obtain significantly better results.

It is clear that the results of the optimization procedure are highly dependent on: criteria for the choice of suitable sites, shape and size of the area of interest, magnitudes and hypocenters depths of interest and optimization criteria. Clearly, these should be evaluated from time to time according to the specific needs and goals we want to achieve.

Acknowledgements. We are grateful to the anonymous reviewers and to the editor Damiano Pesaresi for their constructive comments and suggestions. 


\section{References}

Adelfio, G., Chiodi, M., D’Alessandro, A., Luzio, D., D’Anna, G., and Mangano, G.: Simultaneous seismic wave clustering and registration, Comput. Geosci., 44, 60-69, doi:10.1016/j.cageo.2012.02.017, 2012.

Castello B., Selvaggi G., Chiarabba C., and Amato A.: CSI - Catalogo della sismicità italiana 1981-2002, versione 1.1. INGVCNT, Roma, available at: http://www.ingv.it/CSI (last access: 1 August 2014), 2006.

D'Alessandro, A.: The Marsili Seamount, the biggest European volcano, could be still active!, Current Science, 106, p. 1339, 2014.

D'Alessandro, A. and D'Anna, G.: Suitability of low cost 3 axes MEMS accelerometer in strong motion seismology: tests on the LIS331DLH (iPhone) accelerometer, Bull. Seismol. Soc. Am., 103, 2906-2913, doi:10.1785/0120120287, 2013.

D'Alessandro, A. and Stickney, M.: Montana Seismic Network Performance: an evaluation through the SNES method, Bull. Seismol. Soc. Am., 102, 73-87, doi:10.1785/0120100234, 2012.

D’Alessandro, A., D’Anna, G., Luzio, D., and Mangano, G.: The INGV's new OBS/H: analysis of the signals recorded at the Marsili submarine volcano, J. Volcanol. Geoth. Res., 183, 17-29, doi:10.1016/j.jvolgeores.2009.02.008, 2009.

D’Alessandro, A., Luzio, D., D’Anna, G., and Mangano, G.: Seismic Network Evaluation through Simulation: An Application to the Italian National Seismic Network, Bull. Seismol. Soc. Am., 101, 1213-1232, doi:10.1785/0120100066, 2011a.

D’Alessandro, A., Papanastassiou, D., and Baskoutas, I.: Hellenic Unified Seismological Network: an evaluation of its performance through SNES method, Geophys. J. Int., 185, 1417-1430, doi:10.1111/j.1365-246X.2011.05018.x, 2011b.

D’Alessandro, A., Mangano, G., and D'Anna, G.: Evidence of persistent seismo-volcanic activity at Marsili seamount, Ann. Geophys., Scientific News, 55, 213-214, doi:10.4401/ag-5515, 2012a.

D'Alessandro, A. and Ruppert, N.: Evaluation of Location Performance and Magnitude of Completeness of Alaska Regional Seismic Network by SNES Method, Bull. Seismol. Soc. Am., 102, 2098-2115, doi:10.1785/0120110199, 2012b.

D’Alessandro, A., Danet, A., and Grecu, B.: Location Performance and Detection Magnitude Threshold of the Romanian National Seismic Network, Pure Appl. Geophys., 169, 2149-2164, doi:10.1007/s00024-012-0475-7, 2012c.

D'Alessandro, A., Gervasi, A., and Guerra, I.: Evolution and strengthening of the Calabrian Regional Seismic Network, Adv. Geosci., 36, 11-16, doi:10.5194/adgeo-36-11-2013, 2013a.
D’Alessandro, A., Mangano, G., D'Anna, G., and Luzio, D.: Waveforms clustering and single-station location of microearthquake multiplets recorded in the northern Sicilian offshore region, Geophys. J. Int., 194, 1789-1809, doi:10.1093/gji/ggt192, 2013b.

D’Alessandro, A., Badal, J., D’ Anna, G., Papanastassiou, D., Baskoutas, I., and Özel, M. M.: Location Performance and Detection Threshold of the Spanish National Seismic Network, Pure Appl. Geophys., 170, 1859-1880, doi:10.1007/s00024-0120625-y, 2013c.

D’Alessandro, A., Scarfî, L., Scaltrito, A., Di Prima, S., and Rapisarda, S.: Planning the improvement of a seismic network for monitoring active volcanic areas: the experience on Mt. Etna, Adv. Geosci., 36, 39-47, doi:10.5194/adgeo-36-39-2013, 2013d

Ekström, G., Nettles, M., and Dziewonski, A. M.: The global CMT project 2004-2010: Centroid-moment tensors for 13,017 earthquakes, Phys. Earth Planet. Inter., 200-201, 1-9, doi:10.1016/j.pepi.2012.04.002, 2012.

European-Mediterranean CMT catalog: European-Mediterranean Regional Centroid-Moment Tensors Catalog, available at: http: //www.bo.ingv.it/RCMT, last access: 1 August 2014.

Guerra, I., Harabaglia, A., Gervasi, A., and Rosa, A. B.: The 19981999 Pollino (Southern Apennines, Italy) seismic crisis: Tomography of a sequence, Ann. Geophys., 48, 995-1007, 2005, http://www.ann-geophys.net/48/995/2005/.

ISIDE catalog, Italian Seismic Instrumental and parametric DatabasE, available at: http://iside.rm.ingv.it/iside, last access: $1 \mathrm{Au}-$ gust 2014.

Luzi, L., Hailemikael, S., Bindi, D., Pacor, F., Mele, F., and Sabetta, F.: ITACA (ITalian ACcelerometric Archive): A Web Portal for the Dissemination of Italian Strong motion Data, Seismol. Res. Lett., 79, 716-722, doi:10.1785/gssrl.79.5.716, 2008.

Mangano, G., D’Alessandro, A., and D'Anna, G.: Long-term underwater monitoring of seismic areas: design of an Ocean Bottom Seismometer with Hydrophone and its performance evaluation, OCEANS 2011 IEEE Conference, 6-9 June, Santander, Spain, in: OCEANS 2011 IEEE Conference Proceeding, 9, doi:10.1109/Oceans-Spain.2011.6003609, 2011.

Peresan, A. and Panza, G. F.: UCI2001: The Updated Catalogue of Italy, The Abdus Salam International Centre for Theoretical Physics, ICTP, Miramare, Trieste, Italy, Internal report IC/IR/2002/3, 2002.

Rovida, A., Camassi, R., Gasperini, P., and Stucchi, M. (Eds.): CPTI11, the 2011 version of the Parametric Catalogue of Italian Earthquakes, Milano, Bologna, available at: http://emidius. mi.ingv.it/CPTI, doi:10.6092/INGV.IT-CPTI11, 2011.

Totaro, C., Presti, D., Billi, A., Gervasi, A., Orecchio, B., Guerra, I., and Neri, G.: The ongoing seismic crisis of Pollino Mts in Southern Italy, Seismol. Res. Lett., 84, 955-962, 2013. 